\title{
Extreme winds at northern mid-latitudes since 1871
}

\author{
S. Brönnimann ${ }^{1 *}$, O. Martius ${ }^{1}, \mathrm{H}$. von WAldow ${ }^{1}$, C. Welker $^{1}$, J. Luterbacher $^{2}$, \\ G.P. COMPO ${ }^{3,4}$, P.D. SARDESHMUKH ${ }^{3,4}$ and T. USBECK ${ }^{5,6}$
}

\author{
${ }^{1}$ Oeschger Centre for Climate Change Research and Institute of Geography, University of Bern, Bern, Switzerland \\ ${ }^{2}$ Department of Geography, Climatology, Climate Dynamics and Climate Change, Justus-Liebig University of \\ Giessen, Giessen, Germany \\ ${ }^{3}$ Climate Diagnostics Center, CIRES, University of Colorado, Boulder, USA \\ ${ }^{4}$ Physical Sciences Division, Earth System Research Laboratory, NOAA, Boulder, USA \\ ${ }^{5}$ Swiss Federal Institute for Forest, Snow and Landscape Research WSL, Birmensdorf, Switzerland \\ ${ }^{6}$ Department of Geography, University of Neuchâtel, Switzerland
}

(Manuscript received August 5, 2011; in revised form December 4, 2011; accepted December 4, 2011)

\begin{abstract}
Studying a sufficiently large sample of extremes or analysing the statistics of their occurrence, including trends, is hampered by the length of the existing observation-based record. New data sets such as the Twentieth Century Reanalysis (20CR), which consists of an ensemble of 56 members, significantly extend our record back in time. In this paper, we present examples of extremes of winds at northern hemisphere mid-latitudes in 20CR to illustrate challenges and opportunities for analysing extremes over a longer period than previously possible. For four representative storms from Europe and North America, 20CR provides a relatively good depiction of the synoptic-scale meteorological development, although it misses smaller scale features as well as local effects due to orography. For analysing trends of extreme winds, it is shown that the individual ensemble members should be used, rather than the ensemble mean, which appears to be biased towards lower wind speeds early in the record. For the studied locations, decadal variability and trends can best be characterised after around 1950, when the ensemble variance remains consistent. Different methodological approaches for studying changes in extreme winds are discussed. Finally, we show hemispheric maps of trends in extreme wind speeds since 1950.
\end{abstract}

\section{Introduction}

Some of the largest effects of climate change on societal, economic, and natural systems do not come from changes in the mean state of the climate (to which systems may partly adapt), but arguably from changes in extreme weather and climate. Avoiding or predicting these impacts is of great importance. Consequently, the occurrence of extremes, the processes behind their generation, and their representation in numerical or statistical models have become important research topics. This importance is reflected in the fact that the Intergovernmental Panel on Climate Change (IPCC) has commissioned a Special Report on Extreme Events (IPCC, 2011). As extreme events are usually rare, the limited length of the existing observation-based record is often an important constraint for such studies (see FREI and SCHÄR, 2001). Several projects ${ }^{1}$ work on improving the data coverage for the past and present in order to allow

\footnotetext{
*Corresponding author: Stefan Brönnimann, Oeschger Centre for Climate Change Research and Institute of Geography, University of Bern, Hallerstrasse 12, 3012 Bern, Switzerland, e-mail: stefan.broennimann@ giub.unibe.ch

${ }^{1}$ WMO Mediterranean Climate Data Rescue initiative (MEDARE, www.omm.urv.cat/MEDARE); the European Climate Assessment \& Dataset (ECA\&D, http://ecad.knmi.nl); the European Climate Support Network (ECSN, www.eumetnet.eu.org/ECSN_home.htm); the $6^{\text {th }}$ EU-FP IP Climate change and impact research: the Mediterranean environment
}

studies of extreme events including heatwaves, strong rainfall events, and windstorms. This special section of the Meteorologische Zeitschrift, which is also a followup to a Special Issue in Vol. 18, No. 4 (BRÖNNIMANN et al., 2009), documents the results of some of those efforts (e.g., contributions by SALEK et al., BRÖNNIMANN and COMPO, or USTRNUL et al.).

In this paper we illustrate challenges and opportunities offered by a novel reanalysis product that extends back to 1871 , by using the example of extreme winds in the northern mid-latitudes. Severe windstorms that occurred prior to 1950 have been studied using historical information (e.g., BRÁZDIL and DOBROVOLNY, 2000, 2001; Dobrovolny and BRÁZDIL, 2003; PFISTER et al., 2010; WHEELER et al., 2010), but these studies mostly do not provide quantitative wind information. A number of publications analyse long instrumental wind data mainly from Europe and the North Atlantic region (e.g., JÖNSSON and HOLMQUIST, 1995; JÖNSSON and

(CIRCE, www.circeproject.eu); the HISTALP (www.zamg.ac.at/histalp) and the ALP-IMP projects (www.zamg.ac.at/ALPIMP); the Atmospheric Circulation Reconstructions over the Earth initiative (ACRE,

www.met-acre.org; ALLAN et al., 2011), the Mediterranean Climate Variability and Predictability programme (MedCLIVAR, www.medclivar.eu/), 6th EU-FP IP MILLENNIUM, the $4^{\text {th }}$ and $5^{\text {th }}$ EU-FP projects MEDALUS, ADVICE and IMPROVE; and the NOAA Climate Database Modernization Program (DUPIGNY-GIROUX et al., 2007). 
FORTUNIAK, 1995; SCHIESSER et al., 1997; B ÄRRING and VON STORCH, 2004; B ̈̈RRING and FORTUNIAK, 2009; MATUlla et al., 2008, in press; KRUEGER and VON STORCH, 2011; WANG et al., 2009, 2011 and references therein). However, instrumental wind data are usually only available for a short period, they can be affected by inhomogeneities (e.g., VON STORCH et al., 1993; WASA, 1998; USBECK et al., 2010a,b), and may be of limited spatial representativeness (PFAHL et al., 2009).

Numerical information on wind speed extremes (see PALUTIKOF et al., 1999 for a review), preferably in high-resolution, gridded form, is necessary for estimating wind stress on built structures, insurance loss modelling (KLAWA and ULBRICH, 2003), ecosystems impact modelling (e.g., SCHUMACHER et al., 2004, SCHUMACHER and BUGMANN, 2006), hindcast experiments to address predictability (RENGGLI et al., 2011), studies of atmospheric processes (e.g. WERNLI et al., 2002), and many other applications.

Reanalysis data sets provide this information, but some variables such as maximum wind gusts may not be adequate in reanalyses (e.g., DELla-MARTA et al., 2009; HOFHERR and KUNZ, 2010). FRANK and MAJEWSKI (2006) reconstructed extreme historic storm events from ERA-40 reanalyses by using different models with a spatial resolution ranging from 2.8 to $40 \mathrm{~km}$. Due to its low spatial resolution, however, re-analysis data cannot capture local-scale variations of the terrain that are important for deriving reliable wind fields (e.g. KALTHOFF et al., 2003; FRANK and MAJEWSKI, 2006; HOFHERR and KUNZ, 2010).

Moreover, most reanalyses are not long enough to contain a large sample of extreme storms for a given region. Some authors therefore revert to surface pressure observations from which they deduce wind speeds using geostrophic approximations (e.g., WANG et al., 2009; B ÄRRING and FORTUNIAK, 2009).

Some of the issues above mentioned may be addressed with the new, 140 years long global "Twentieth Century Reanalysis", version 2 (20CR in the following; CoMPO et al., 2011). 20CR is an ensemble product, i.e., it consists of 56 members, each of which is physically consistent and equally likely. This data set provides a new opportunity to extend the analysis time horizon back into the past. Storms that were previously in the realms of historical science or even paleoclimatology, with often only few point observations available for analyses, can now be studied quantitatively and in three dimensions.

However, this also raises the need to characterize the data set's suitability for addressing specific research questions and to assess the information content in the ensemble mean and in the individual ensemble members. In this paper we illustrate the challenges by looking at two main research questions:
1. Can we use 20CR together with historical information to obtain quantitative information on historical high-impact storms to consistently supplement the hitherto available record?

This would be beneficial for several reasons: Process studies could identify mechanisms, impact modelling could make use of the additional cases, weather forecasters could use historical cases as analogs, and applications that require spatial extrapolation could benefit from a better spatial coverage of extreme events.

2. Can we use 20CR to characterize decadal to multidecadal variability in extreme winds over the past approximately 140 years?

Answering this question requires that the data are of sufficient quality to address subtle changes over long time periods. Further, it requires that the uncertainties in the data and in the statistical modelling can be quantified or estimated (see also WANG et al., 2011, DoNAT et al., 2011).

In this paper, we use four storms as examples, the recent, well studied storm "Kyrill" which hit Europe in 2007 (e.g., FINK et al., 2009) and three historical storms. These storms include the one causing the "Tay Bridge disaster" in Scotland in 1879 (BURT, 2004), a Föhn storm in Switzerland in 1919 (FREY, 1926), and the "Armistice Day storm" in the USA in 1940 (KNARR, 1941). These storms are representative of extreme wind situations in Europe and North America, all of which were related to extratropical cyclones. For these four cases, we combine 20CR with historical information to discuss the first question, namely to what extent we can increase our sample of storm events and what we can possibly learn from the ensemble members as compared to the ensemble mean. We touch upon the subject of how extreme events can be defined and what statistical frameworks we have to describe them and their changes over time. We use historical observations and 20CR to demonstrate applications of extreme value theory. Next, we extend the analysis in time to address decadal to multidecadal changes in extreme winds at the locations of the three historical storms. In this context, we address the second question, i.e., whether or not the data are suitable for long-term trend analyses of extreme winds and to what extent we can increase our knowledge from analysing individual ensemble members. Finally, the study is extended into space by showing maps of trend statistics of extreme winds.

\section{Data and methods that allow studying wind extremes over 140 years}

\subsection{Data}

In this study we use the newly-released Version 2 of 20CR. This is a global 3-dimensional atmospheric reanalysis dataset at approximately $2 \times 2^{\circ}$ spatial resolution and 6-hour temporal resolution reaching back 
to 1871 (COMPO et al., 2011). To resolve the atmosphere's vertical structure, traditional global reanalysis products depend on the assimilation of radiosonde data, which until recently were not available further back than about 1948 (TRUCHELUT and HART, 2011). In contrast, 20CR provides analyses based on assimilation of surface and sea level pressure observations, which reach further back in time. Boundary conditions were derived from monthly mean sea surface temperature and sea ice distributions from the HadISST data set (RAYNER et al., 2003).

The data assimilation was performed using an Ensemble Kalman Filter (EnKF) technique, with first guess fields generated by a 2008 experimental version of the US National Center for Environmental Prediction Global Forecast System atmosphere/land model (NCEP/GFS). The GFS model was integrated at a resolution of T62 in the horizontal and 28 hybrid sigmapressure levels in the vertical. The ensemble contains 56 members (see COMPO et al., 2011 for details).

The data set is increasingly used for studying midlatitude storm activity (WANG et al., 2009; DONAT et al., 2011). Good agreement is generally found with existing reanalysis products for the past 40-60 years, but less is known about the quality in earlier times. In this study we analyse horizontal winds at the lowest model level (0.995 sigma level, ca. 30-40 m above ground), every 6 hours. These data were compared to wind observations. For one location (Zurich, Switzerland), homogenised instrumental wind observations were available back to 1891 in the form of daily maxima of the hourly wind speeds, albeit only for the extended winter season (October to March) (USBECK et al., 2010a,b). Further historical wind data are used for the individual case studies from the Annals of METEOSWISS or from contemporary publications, including historical upper-level wind observations from pilot balloon ascents from the Comprehensive Historical Upper-Air Network (CHUAN; STICKLER et al., 2010).

For the case study of windstorm Kyrill, we compare 20CR with daily maximum 3-second average surface wind gust data of measuring stations in Germany provided by the European Climate Assessment \& Dataset project ECA\&D (KLOK and KLEIN TANK, 2009; data retrieved 15 July 2011 from http://eca.knmi.nl/). 20CR is additionally compared with ERA Interim, the latest ECMWF reanalysis product spanning the period 1979 to present (DEE et al., 2011). Here, we analyse $10 \mathrm{~m}$ horizontal wind at a spatial resolution of $1.5^{\circ} \times 1.5^{\circ}$ and a temporal resolution of 6 hours.

\subsection{Defining extreme storms}

The notion of "extreme weather event" or "extreme storm" in particular has no single definition. The term "extreme" in this context is often used synonymously with "high impact" or "severe". A basic distinction can be made according to whether the classification is based on the hazard posed by the weather event (see also KLEIN TANK et al., 2009), or on the impact, i.e. in terms of loss of human lives, economic damage, or ecosystem disturbance. In the following, we focus on the hazard only.

A storm's hazard is usually assessed by the magnitude of meteorological variables such as wind gust speed or by a derived index that empirically relates meteorological variables to potential damage, e.g. the cubed maximum wind gust speed or a cubed maximum wind, normalised with respect to some climatological quantile such as $98 \%$ (KLAWA and UlbRICH, 2003). Also, the spatial characteristics and the duration of a storm are relevant quantities in this context, which may be incorporated in indices (e.g. DELlA-MARTA et al., 2009).

For instance, maximum wind gust speeds are not as high in extratropical cyclones as in tropical cyclones, but the area affected by high wind speed is much larger for the former compared to the latter (JOHNSON and MIAYNISHI, 2007). The picture becomes even more complex when other meteorological elements in addition to wind (e.g., temperature and precipitation) add to the storm hazard (see also STEPHENSON, 2008).

In this study we define extremes in terms of one variable, wind speed, using statistical definitions. We use the annual maxima (termed $\max _{a n n}$ ) as well as the annual $98^{\text {th }}$ percentiles (termed $p 98_{\text {ann }}$ ) of 20CR 6hourly wind speed at the 0.995 sigma level. A threshold related to the local $98^{\text {th }}$ percentile of the climatology is frequently used in the literature (KLAWA and ULBRICH, 2003; LECKEBUSCH et al., 2007; SCHWIERZ et al., 2010).

The annual maximum wind speed is a measure of the intensity of relatively extreme storms. The 98 percentile corresponds to the wind speed that is exceeded on average on 7 days per year and hence might reflect both the intensity (e.g., in regions with many storms) and the frequency (e.g., in regions with very few storms) of storms.

\subsection{Statistical analyses of extremes}

For statistically defining and modelling extremes in a single time series, two canonical methodological approaches exist (COLES, 2001). The "block" approach considers maximum values of a variable over suitably long periods of time (e.g., a month or a year). The "peak over threshold" (POT) approach classifies a wind event as an extreme event when it exceeds a predefined threshold. The threshold may be defined as a high quantile of the variable's local climatological distribution, or as an absolute threshold above which the event poses a severe hazard for humans, buildings, infrastructure, or ecosystems. A threshold defined relative to the local climatology takes into account that anthropogenic structures and biota likely are adapted to the wind regime and therefore better matches the colloquial meaning of "extreme storm" as a hazardous event (e.g. SCHWIERZ et al., 2010). 

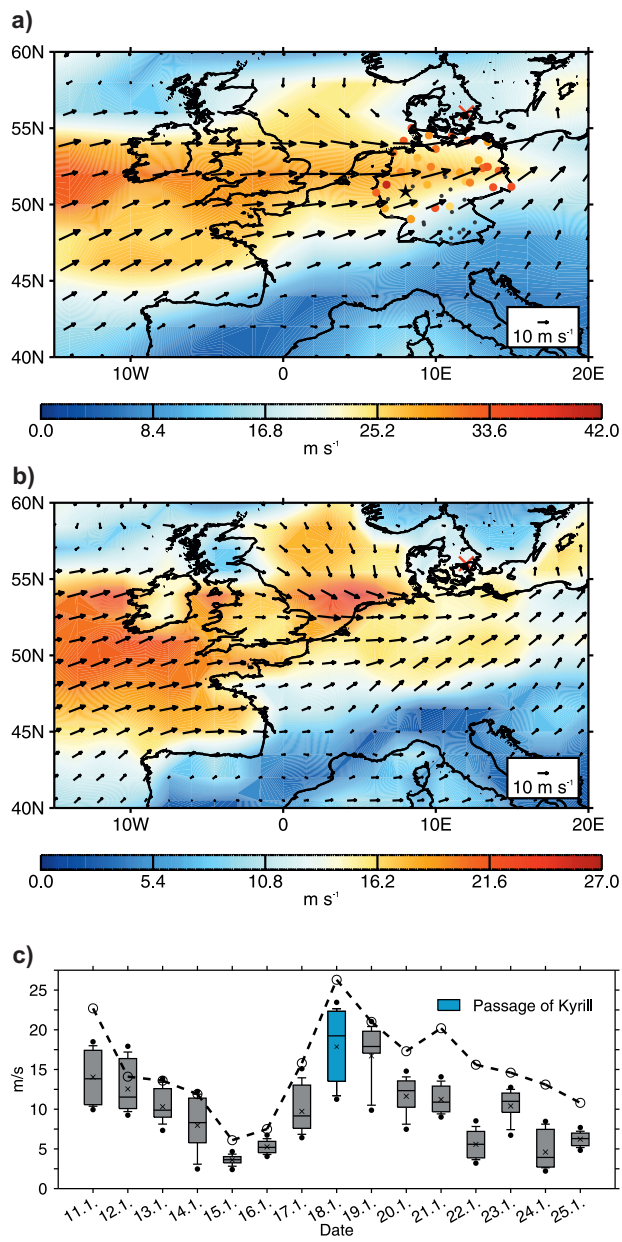

Figure 1: Kyrill, 18 January 2007. a) 20CR 0.995 sigma level wind vectors from the ensemble mean for 18 UTC as well as the maximum among all 56 ensemble members of the maximum daily wind speed (coloured contours). The red cross indicates the minimum surface pressure position of Kyrill at 18 UTC (according to PASCAL, 2010). Coloured dots show the location and magnitude of ECA\&D daily maximum 3 second average wind gust observations at German measuring stations. Stations at an elevation above $300 \mathrm{~m}$ asl are plotted as smaller grey dots. The black star denotes the German district Siegen-Wittgenstein. b) Same as a) but for ERA Interim $10-\mathrm{m}$ wind (note the different colour scale and spatial resolution of the data, i.e. $1.5^{\circ} \times 1.5^{\circ}$ ). c) $20 \mathrm{CR}$ ensemble distribution (box plots give min, $p 10, p 25, p 50, p 75, p 90, \max$, and mean (cross)) of daily wind speed at the 0.995 sigma level for the 20CR grid point closest to Siegen-Wittgenstein and a time period in January 2007 (the day Kyrill crossed Siegen-Wittgenstein is marked). Additionally, for the measuring station closest to the latter grid point and for the chosen period, time series of ECA\&D daily maximum 3 second mean wind gust observations are shown (circles and dashed line).

According to Extreme Value Theory (EVT) the distribution of block maxima converges to a member of the family of generalised extreme value distributions (GEV, see COLES, 2001). The GEV is indexed by a location-, a scale-, and a shape-parameter. The advantage of using a model such as the GEV to describe the behaviour of extreme values is to make predictions about values that are larger than what has been observed so far. In the
POT approach, it is assumed that the excesses over that threshold are asymptotically distributed according to a Generalised Pareto Distribution (GPD) (see DAVISON and SMITH, 1990, and RoOTZEN and TAJVIDI, 1997 for more details on the POT approach).

In this paper we use both approaches. The POT approach is used to compare the distributions of extremes between observations and 20CR (we use a threshold based on the $93^{\text {rd }}$ percentile of the daily maxima, as detailed in Sect. 4). The block maxima approach is used for analyzing long term changes and trends in extreme wind speed.

To apply the POT model to environmental timeseries, a number of issues have to be dealt with, which are related to the assumptions of independence and stationarity of the data. Non-stationarity of wind speed time-series occurs at different time-scales:

1) Serial dependence or clustering

Because extreme winds in Europe are often associated with synoptic scale cyclones that have a lifetime of several days (e.g. WERnLI et al., 2002) several extreme wind events can occur during the passage of a cyclone. Extreme events have hence to be declustered by selecting only one event per cyclone passage (DAVISON and SMITH, 1990). To separate individual clusters, the wind values have to fall below the threshold for an empirically determined time period $r$. We chose $r=3$ days, a value that is consistent with the literature (PALUTIKOF et al., 1999; Della-MARTA et al., 2009) and the typical lifetime of extratropical cyclones.

2) Seasonality

The wind maxima exhibit a distinct seasonal pattern with more frequent and more intense events during winter (Klawa and UlBRICH, 2003, DONAT et al., 2011). A process called "prewhitening" is sometimes used to extract a stationary part of a time series (DAVISON and SMITH, 1990). In this study, this is not necessary since we only analyse the winter season (December to February).

\section{3) Multi-decadal variations}

Multi-decadal variations of wind extremes are present in reanalysis data (DONAT et al., 2011) and observations (MATUlla et al., 2008). We apply a non-parametric smoother (loess, span $=0.3$ ) to the $93^{\text {rd }}$ percentile of the daily maxima in the winter season to remove the lowfrequency variability. This approach is similar to, but much more basic than, the methods used by COELHO et al. (2008) and KYSELY (2010) to analyse temperature extremes.

\section{Examples of storm events}

\subsection{Kyrill (2007)}

The very intense windstorm Kyrill hit Western/Central Europe on 18 January 2007. It affected an anomalously large area over land and caused widespread damage and 
fatalities (e.g., FINK et al., 2009). Kyrill caused uprooting of millions of trees in Central Europe, in particular in the low mountain ranges of the German Sauerand Siegerland. Figure 1a shows the 20CR ensemble mean near-surface (i.e., 0.995 sigma level) horizontal wind field over parts of Europe on 18 January 2007, 18 UTC. At this approximate time, very high winds associated with Kyrill occurred in the German district Siegen-Wittgenstein (denoted with a black star), located in the Siegerland region, and caused major forest damage through windthrow. The centre of Kyrill (indicated with a red cross), i.e., its minimum surface pressure position, was several hundred kilometres to the north-east at this time. In Figure 1a, we also compare for 18 January 2007 , daily maximum wind speeds at the 0.995 sigma level in the 20CR ensemble (i.e., the ensemble maximum of the daily maximum of 4 times daily winds) with daily maximum 3 second average surface wind gust observations according to the ECA\&D data set. For reasons of clarity, only German measuring stations are plotted. Given the temporal mismatch between 3 -second gusts and the maximum of 6 hourly winds, the general picture shows good agreement, the high-resolution observations show spatial variability at scales that are much smaller than resolved by 20CR. We also find a generally good spatial agreement of 20CR near-surface winds with ERA Interim surface (i.e., $10 \mathrm{~m}$ ) winds (Figure 1b). The most obvious differences between 20CR and ERA Interim are land-sea wind speed (colour shading) gradients which are seen in ERA Interim but to a lesser extent in 20CR. This difference is likely due to the comparison of $10-\mathrm{m}$ wind data with 0.995 sigma level wind data.

For Siegen-Wittgenstein the temporal wind evolution is well depicted in 20CR during a 15-day period in January 2007 (including 18 January 2007), when compared with observations (Figure 1c). The Pearson correlation coefficient between the time series of the daily maximum wind speed at the 0.995 sigma level of the 20CR ensemble (upper black dots) and the observed maximum wind gusts (circles and dashed line) is 0.87 .

\subsection{Historical storms}

The example of Kyrill shows that, in principle, a data set based on the assimilation of surface and sea level pressure only is able to realistically represent severe storms. If this was also true for events in the first half of the twentieth century and earlier when surface observations were sparser, 20CR could be used to enlarge the sample of extreme storms available for quantitative studies. The top row of Figure 2 shows 20CR wind fields for the three previously mentioned historical storms (solid arrows), together with partially sparse wind measurements (grey dashed arrows). The impact of each event is depicted in the middle row. In general, photos and depictions are important sources for historical extreme events, especially for the assessment of impacts. The bottom row shows the temporal evolution of wind speed at the nearest 20CR grid point during the individual events.

The first example is a storm that hit Scotland on 28 December 1879. It is notorious because it killed 75 people (BURT, 2004) and destroyed the Tay bridge - the much admired, brand new, longest bridge in the world at that time (Figure 2, central row, left). The storm was strong, but according to BURT (2004) less severe than a few other well-known storms in Scotland.

According to contemporary pressure observations and analyses by LAMB (1991) the synoptic situation was characterised by a strong surface low located between Iceland and Norway on 28 December 1879 and a secondary smaller-scale low pressure system that reached the Outer Hebrides in the evening of 28 December 1879. The triple point of the occluding frontal systems of the second low pressure system was located over the Firth of Tay at that time (LAMB, 1991) and strong winds were accompanying this second surface depression as it moved northeastward on a track to the north of the Firth of Tay. In 20CR, this small-scale feature is visible as a short wave in the surface pressure, however the structure is less distinct than in the analysis of Lamb. The strong Icelandic low pressure system had a minimum sea level pressure of $952 \mathrm{hPa}$. The upper-level fields from the 20CR show that the secondary low formed in the left exit region of a strong jet over the Atlantic. BURT (2004) reports maximum wind speeds of ca. $36 \mathrm{~m} / \mathrm{s}$, with possible gusts up to ca. $47 \mathrm{~m} / \mathrm{s}$ in the Firth of Tay region for the evening of the day. Local factors, among them the west-east orientation and topographical features of the Firth of Tay, could have contributed to the high wind speeds (BURT, 2004).

Although some ensemble members reach peak winds of approximately $25 \mathrm{~m} / \mathrm{s}$ at the 0.995 sigma level, the wind maxima are clearly weaker in $20 \mathrm{CR}$ than in these reports. The 0.995 sigma level wind field from the 20CR ensemble mean on 29 December 1879, 0 UTC, shortly after the collapse of the bridge, shows west-southwesterly winds in Scotland reaching approximately $20 \mathrm{~m} / \mathrm{s}$. Note, however, that a comparison of absolute values is extremely difficult because the historical data are only estimations and because the 0.995 sigma level does not represent the surface and is given on a relatively coarse grid.

The temporal development of the 0.995 sigma level winds near Dundee (lowest panel) fits very well with contemporary reports summarised by LAMB (1991) and BURT (2004). BURT (2004) mentions that the wind was already strong during the previous night and morning. After this first wind maximum the winds weakened during the day and freshened up again at the evening of the 28 December 1879. The first wind maximum was associated with the passage of the main cyclone, the second wind maximum was due to the passage of the secondary cyclone that formed in the left jet exit area and moved eastward relatively fast. This temporal evolution is cap- 
Tay bridge storm

0.995 sigma wind, 29-Dec-1879, 0 UTC
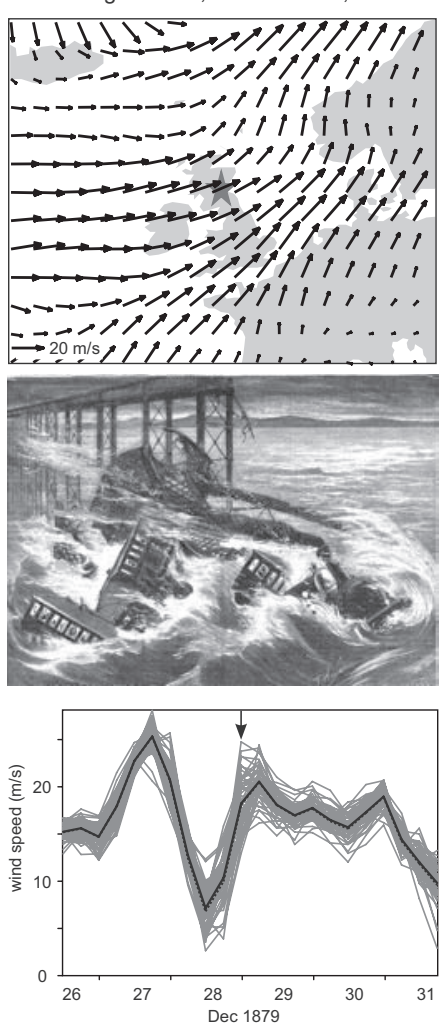

Föhn storm Zurich 0.995 sigma wind, 5-Jan-1919, 12 UTC
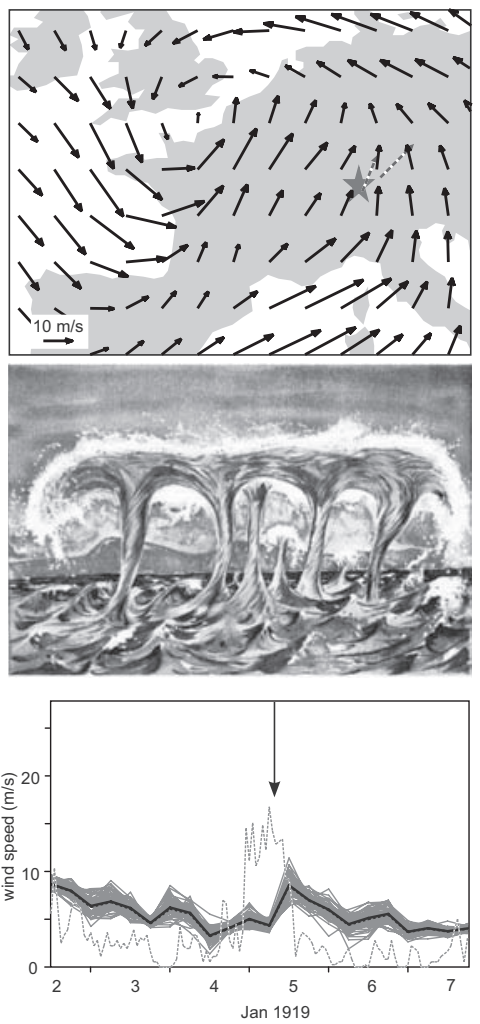

Armistice Day storm

$1000 \mathrm{~m}$ asl wind, 12-Nov-1940, 0 UTC
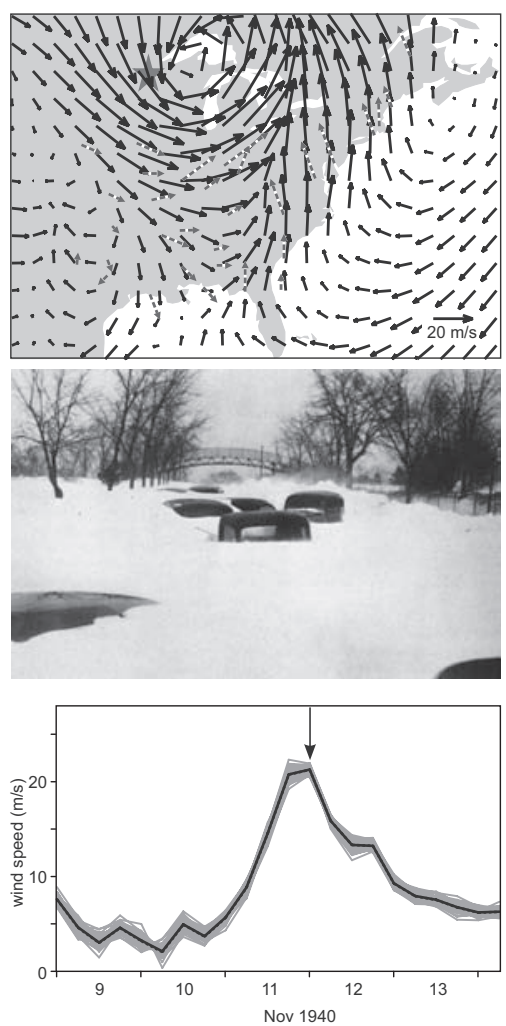

Figure 2: Case studies of three historical storms: The Tay Bridge disaster in Scotland in December 1879 (left column), a Föhn storm in Switzerland in January 1919 (middle column), and the Armistice Day storm in the USA in November 1940 (right column). In the top row, for the individual cases, the 0.995 sigma level wind field from the 20CR ensemble mean is shown as black arrows together with sparse observations near the ground as grey dashed arrows (except for the Armistice Day storm, where the 20CR wind field at $900 \mathrm{hPa}$ and wind measurements at $1000 \mathrm{~m}$ asl according to the CHUAN data set are plotted). Star symbols denote the approximate geographical locations of the events. The middle row shows contemporary depictions of the events (left: illustration from Christian Herald, 7 January 1880, middle: drawn from hand sketches of an observer at the right bank near Uerikon, Lake Zurich, Reprod. Hofer \& Co. AG, Zürich, from FREY, 1926, right: Excelsior Boulevard, west of Minneapolis, after the Armistice Day Storm, courtesy: Minnesota Historical Society). The bottom row shows for the corresponding 20CR grid point closest to the single event the temporal evolution of 20CR wind speed at the 0.995 sigma level (or $900 \mathrm{hPa}$ respectively) for the ensemble mean (solid black line) and the individual ensemble members (grey lines). Additionally, in the bottom middle panel, local hourly wind speed observations from Zurich are denoted as a grey dashed line. The vertical black arrows indicate the instants of time of the wind field depictions (top row).

tured very well in 20CR. In fact, all 56 ensemble members show this behaviour. In 20CR the first episode of the storm was stronger than the second (but the ensemble spread is larger for the second part than for the first).

The second event is a Föhn storm in Switzerland that occurred on the morning of 5 January 1919. Several eyewitness accounts reported waterspouts on lake Zurich (FREY, 1926; a contemporary sketch is shown in Figure 2), which is a very rare phenomenon. Föhn is a local wind which is induced by the interaction of the synopticscale pressure and wind fields with the Alps. The Föhn winds are heavily modified by local effects and the shape of alpine valleys (e.g., WEBER and FURGER, 2001). The prediction of whether Föhn winds reach the valley surface or not is still a major forecasting challenge (e.g., DRECHSEL and MAYER, 2008). For 5 January 1919, 20CR shows peak winds of around $10 \mathrm{~m} / \mathrm{s}$ near the sur- face in the region of Zurich at the time of the event. This wind magnitude is not extreme in absolute terms, also compared with the peak winds during the Tay Bridge disaster or Kyrill. Arguably, the Föhn storm was stronger up-valley (as well as in other Föhn valleys such as the Rhine valley, where this storm is still known as the worst Föhn storm in history) and barely reached to the city centre of Zurich.

The anemometer data (from the Annals of MeteoSwiss) from Zurich and Mt. Säntis (2700 m asl, approximately $70 \mathrm{~km}$ east of Zurich) indicate stronger $(15 \mathrm{~m} / \mathrm{s})$ winds, with a stronger westerly component than 20CR. However, in Zurich, just one hour earlier southerly winds were measured and two hours earlier southeasterly winds. Hence, the difference in wind direction between 20CR and observations is apparently due to the timing of the event, which again might be lo- 


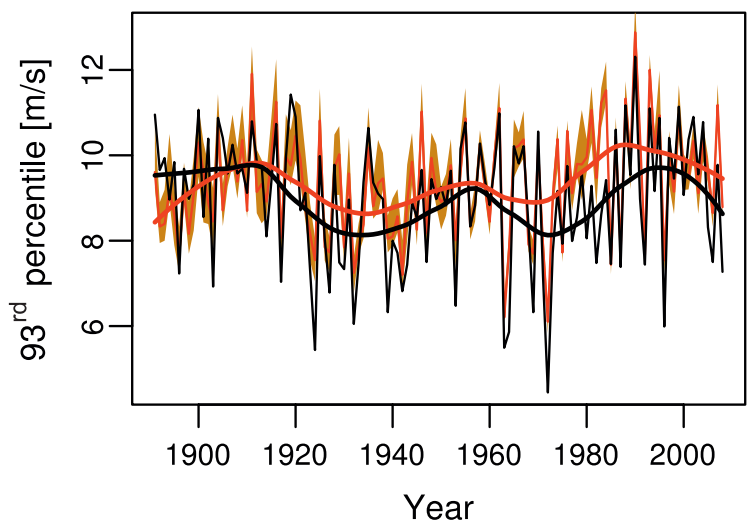

Figure 3: The seasonal 93rd percentile (p93) for ZHOBS (black), ZHMEAN (red), and for the range of ZHMEM (orange shade). The thick lines display the smoothed p93 for ZHOBS (black) and ZHMEAN (red)

cally influenced. The time series of observed wind speed clearly shows the time window when the Föhn wind reached the valley floor in the lake Zurich region (Figure 2, bottom centre). Before and after this window, the wind regime was substantially different. The $20 \mathrm{CR}$, due to its coarse $2^{\circ} \times 2^{\circ}$ spatial resolution, does not resolve the alpine topography well (e.g., in the case of Zurich the elevation difference between model topography and real topography amounts to around $400 \mathrm{~m}$ ). We do not expect that local wind phenomena such as a Föhn storm in an alpine valley are represented accurately. Nevertheless, we expect 20CR to represent the general synoptic situation.

The last case we want to discuss is the Armistice Day storm (or blizzard) which affected the northern Midwestern United States on 12 November 1940. On 10 and 11 November 1940, the low pressure system associated with this event was moving northward across Minnesota, Wisconsin, and the Lake Michigan region and brought moist air from the Gulf of Mexico northward ahead of the cold front and very cold Arctic air southward behind the cold front (see KNARR, 1941; STICKLER et al., 2010). As a consequence, in the northern Midwest, temperatures dropped by up to $24 \mathrm{~K}$ within just over 12 hours, a blizzard brought massive amounts of snow, and wind speeds increased to approximately $30 \mathrm{~m} / \mathrm{s}$ (KNARR, 1941). The storm caused some 150 fatalities, although exact numbers differ depending on the source. In the top right panel of Figure 2, we show the wind field at $900 \mathrm{hPa}$ from 20CR as well as winds at 1000 $\mathrm{m}$ asl from pilot balloon observations from CHUAN. At this level, the surface influences are small and the synoptic features appear more clearly. The agreement between 20CR and CHUAN is very good both in terms of speed and direction. In Minneapolis (location denoted with a star) and near the surface (i.e., at the 0.995 sigma level), 20CR shows ensemble mean wind speeds around $20 \mathrm{~m} / \mathrm{s}$ (lowest panel). In this case, the ensemble spread is very small, i.e., each individual ensemble member gives a very similar depiction of the magnitude of the storm.

\subsection{On the usefulness of 20CR for studying individual storms}

In all four cases of northern mid-latitude storms discussed before, the synoptic scale development of the storms was well reproduced in 20CR. Taking into account the expected limitations due to resolution, 20CR reproduced also the local conditions partially well. Can we thus use the new atmospheric reanalysis data sets and historical information to obtain quantitative information on historical windstorms? In the following each of the four storms is used to highlight a potential application of the 20CR.

The windstorm Kyrill caused uprooting of millions of trees in Central Germany. A potential application of $20 \mathrm{CR}$ could be to study the forest damage and regrowth using a dynamic vegetation model (e.g., LANDCLIM, SCHUMACHER et al., 2004), which usually require atmospheric input data at a high resolution. 20CR captures the main features of Kyrill well and could be used as a basis for dynamical downscaling in order to generate input data for this kind of models. The Tay Bridge storm suggests that 20CR could be used to estimate maximum wind stress for constructions. For such applications empirical functions are often used (e.g., for maximum wind gust speed see JUNGO et al., 2002). The calibration of the latter may account for the fact that 20CR does not capture small-scale, short-term wind extremes. In the case of the Föhn storm on lake Zurich, a possible application could be to estimate wave height. A multi-nested dynamical downscaling and coupling to a wave model would be necessary, which would be extremely challenging with any driving data set. Finally, in the case of the Armistice Day blizzard, potential studies of atmospheric dynamics can directly use 20CR output.

In all, the strength of $20 \mathrm{CR}$ lies in the fact that it well represents the synoptic-scale features of storms, and in this respect it certainly extends our "sample" of cases.

\section{The distribution of extreme winds in Zurich in observations and 20CR}

In this section we illustrate the application of EVT to long time series of wind speed by modelling and comparing the extreme value distributions of extreme wind events extracted from Zurich station data, ZHOBS, the 20CR ensemble mean, ZHMEAN, and the 56 individual 20CR ensemble members, ZHMEMi (see section 2 for details). ZHMEAN and ZHMEMi refer to the daily maxima of the 6 hourly wind speeds at the 0.995 sigma level at the grid point closest to Zurich $\left(48^{\circ} \mathrm{N}\right.$, $8^{\circ} \mathrm{E}$ ). We extracted the winter seasons (DJF) from $1891 / 92$ to $2007 / 08$ and calculated the seasonal $93^{\text {rd }}$ percentile (p93). The seasonal $93^{\text {rd }}$ percentile was chosen because the number of selected extreme events ( 7 days per winter season) roughly corresponds to the established annual $98^{\text {th }}$ percentile under the assumption 

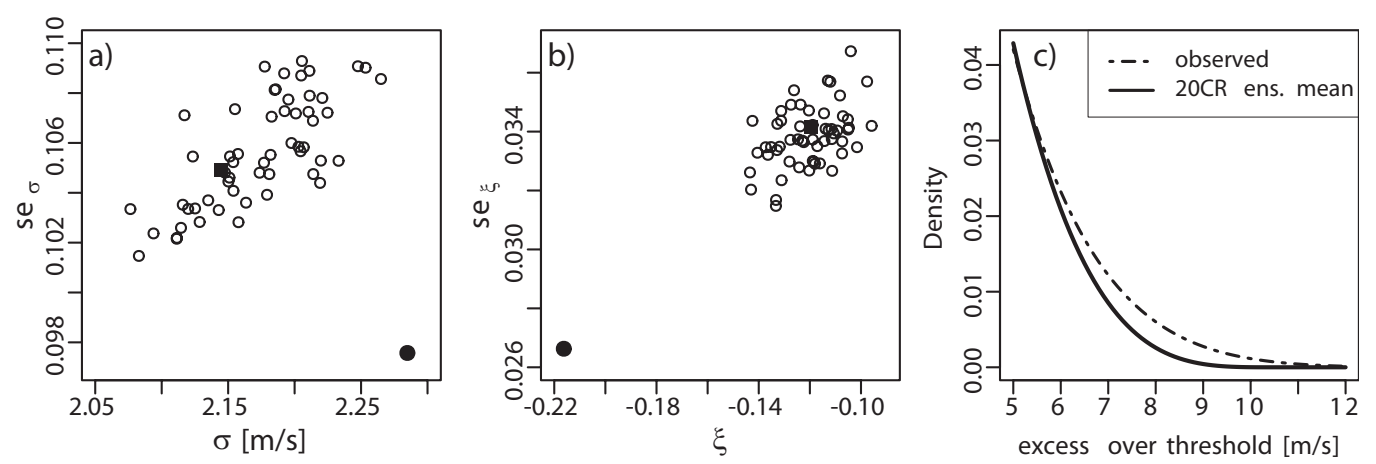

Figure 4: The estimated scale parameters, $\sigma$ (a), and the estimated shape parameters, $\xi$ (b). The respective point estimates are plotted on the $\mathrm{x}$-axis, and the corresponding standard error on the y-axis. Open circles refer to the ZHMEMi, the filled circles to ZHOBS, and the filled squares to ZHMEAN. Panel (c) shows the modelled probability density functions of ZHMEAN (solid line) and ZHOBS (dashed line), focused on the part where the difference is greatest.

that all storms occur during the winter season (see section 2). We used the non-parametric regression method loess (CLEVELAND et al., 1992), with parameter span $=0.3$, to smooth all time series. The smoothing parameter is the lowest one that yields 3 maxima and 2 minima between 1891 and 2008. Thus, the timescale of the smoothed signal's variability ( $\sim 45$ years) is consistent with that of multi-decadal climate variability such as the AMO (DIJKSTRA et al., 2006 and references therein).

Figure 3 shows p93 for ZHOBS (black), ZHMEAN (red), and for the range of ZHMEM (orange shade). The thick lines in Figure 3 display the smoothed p93 for ZHOBS (black) and ZHMEAN (red). The agreement between ZHOBS and ZHMEAN is very good, both on interannual and multi-decadal scales, and the Pearson correlation coefficient between the two time series is 0.79 . With the exception of the first 20 years, the smoothed p93 of ZHOBS is always lower than that of ZHMEAN, but the difference never exceeds $1.2 \mathrm{~m} / \mathrm{s}$. The reason for the change in the difference is not known. The amplitude of the smoothed p93 of ZHOBS is greater than that of ZHMEAN (remember that ZHMEMI is at $40 \mathrm{~m}$ above ground).

We used the maximum likelihood method (COLES, 2001) to fit stationary GPDs to ZHOBS, ZHMEAN, and each ZHMEM individually. The smoothed p93 was used to set the annually varying threshold for these fits. Threshold Selection Plots and Mean Residual Life Plots (COLES, 2001) indicate the validity of this choice (not shown). Before fitting, the time series of threshold exceedances were declustered with run length $r=3$ days. We checked the model fit by visually inspecting the Residual Probability Plots and the Residual Quantile Plots (COLES, 2001), which confirm the validity of the modelling approach (not shown).

Figures 4 a) and b) show the estimated scale parameters, $\sigma$, and the estimated shape parameters, $\xi$, respectively. The respective point estimates are plotted on the $\mathrm{x}$-axis, and the corresponding standard error on the $\mathrm{y}$ - axis. Open circles refer to the ZHMEMi, the filled circles to ZHOBS, and the filled squares to ZHMEAN. The parameters estimated from the ensemble mean roughly equal the mean of the parameters estimated from the individual ensemble members. The scale parameter estimate of ZHOBS $(2.28 \mathrm{~m} / \mathrm{s})$ is greater than the one estimated from 20CR data $(2.14 \mathrm{~m} / \mathrm{s})$, and the shape parameter estimated from ZHOBS $(-0.216)$ is lower than the estimate from 20CR data (-0.120). The overall effect on the difference of both distributions is small: Figure $4 \mathrm{c}$ ) shows both probability density functions, focused on the part where the difference is greatest. The distribution of ZHOBS has a fatter tail.

Overall this comparison shows that distributions of extreme winds in Zurich are similar in observations and 20CR and that the distribution obtained from the ensemble mean cannot be distinguished from those obtained from the ensemble members.

\section{Multidecadal variability of extreme events}

\subsection{Temporal evolution of extremes in the studied cases}

If $20 \mathrm{CR}$ is able to reproduce single storm events, is it also suitable to study long-term changes in the characteristics of storms? In this section we address this question exemplarily for the three locations in Figure 2, i.e., the 20CR grid points closest to Dundee, Zurich, and Minneapolis.

We calculated time series of $\max _{a n n}$ and $p 98_{a n n}$ covering the period 1871-2008 for each ensemble member. For each year we present the distribution of the ensemble using the minimum, the 10-, the 25-, the 50-, the 75, and the 90-percentiles, the maximum and the mean of the ensemble, denoted $\min _{\text {ens }}\left(p 98_{\text {ann }}\right.$, $p 10_{\text {ens }}\left(p 98_{\text {ann }}\right), \quad p 25_{\text {ens }}\left(p 98_{\text {ann }}\right), \quad p 50_{\text {ens }}\left(p 98_{\text {ann }}\right)$, $p 75_{\text {ens }}\left(p 98_{a n n}\right), p 90_{\text {ens }}\left(p 98_{a n n}\right), \max _{\text {ens }}\left(p 98_{a n n}\right)$, and 

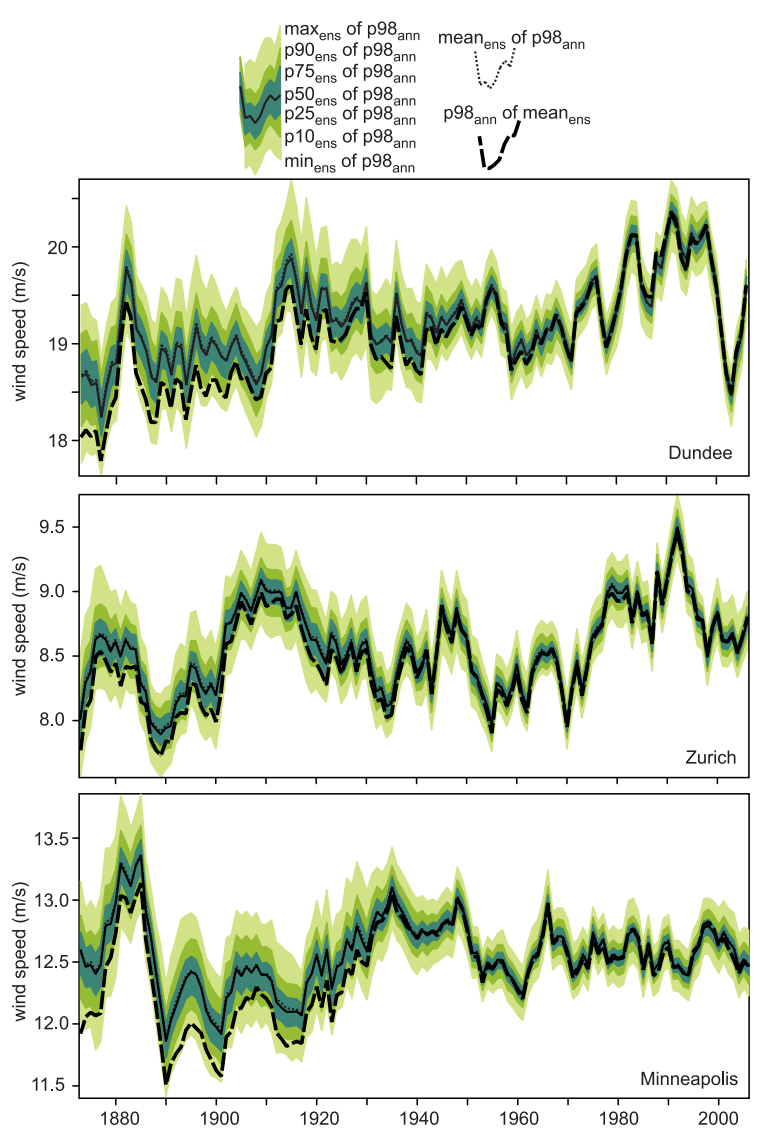

Figure 5: Ensemble distributions for $p 98_{a n n}$ (for definition see text) from 1871 to 2008, for the three locations in Figure 2, i.e. the 20CR grid points closest to Dundee (top), Zurich (middle), and Minneapolis (bottom). The green shading and solid black line indicates the range covered by the ensemble members (i.e, $\min _{e n s}\left(p 98_{a n n}\right), p 10_{\text {ens }}\left(p 98_{a n n}\right), p 25_{\text {ens }}\left(p 98_{a n n}\right)$, $p 50_{\text {ens }}\left(p 98_{\text {ann }}\right), \quad p 75_{\text {ens }}\left(p 98_{\text {ann }}\right), \quad p 90_{\text {ens }}\left(p 98_{\text {ann }}\right), \quad$ and $\max _{e n s}\left(p 98_{a n n}\right)$ and the dotted thin black line indicates the ensemble mean, mean $\left._{\text {ens }}\left(p 98_{a n n}\right)\right)$. The thick dashed black line gives the annual $98^{\text {th }}$ percentile of the 6-hourly wind speed at the 0.995 sigma level calculated from the ensemble mean, $p 98_{a n n}\left(\right.$ mean $\left._{e n s}\right)$. All time series are smoothed with a 5-yr moving average.

mean $_{\text {ens }}\left(p 98_{a n n}\right)$. The latter was compared with the 98-percentile of the 6-hourly wind speed calculated from the ensemble mean wind vector components, $p 98_{a n n}\left(\right.$ mean $\left._{\text {ens }}\right)$. These time series are plotted in Figure 5 (smoothed for visualization purposes).

In Dundee $\left(p 98_{a n n}\right)$ values increased up to the 1990s followed by a sudden drop. The increase in extreme wind speeds between the 1960s and 1990s and the decrease thereafter agree with previous studies (ALEXANDERSSON, et al. 2000; WANG et al., 2009; DONAT et al. 2011) and may be related to the concurrent variability in the North Atlantic Oscillation towards a positive phase up to the 1990s and subsequent reversal (e.g. HuRRELL et al., 2003).

At Zurich, the peak in mean $_{\text {ens }}\left(p 98_{a n n}\right)$ in the 1990 s is particularly strong, but high values are also

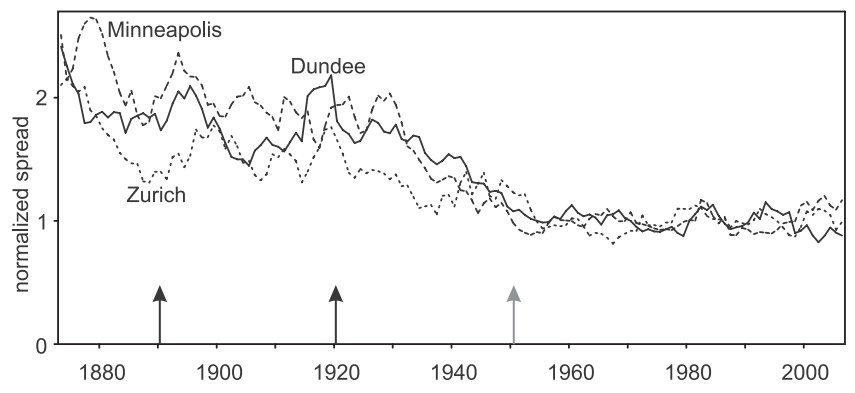

Figure 6: Time series of the difference $\max _{e n s}\left(p 98_{a n n}\right)-$ $\min _{\text {ens }}\left(p 98_{a n n}\right)$ for the three locations. For comparability purposes, the series were divided by their respective 1950-2008 mean values. Vertical arrows indicate changes in the variance inflation factor.

found for the 1900-1920 period, whereas lower values for $\operatorname{mean}_{\text {ens }}\left(p 98_{a n n}\right)$ and meanens $\left(\max _{a n n}\right)$ are found for the decades in between. PFISTER (2009) argues for a "disaster gap" in Switzerland, i.e., a reduced frequency of natural catastrophes in Switzerland, which according to him, however, extends over the period between the 1880s and the 1970s. At Minneapolis (bottom figure), there is no clear long term trend in either mean $_{\text {ens }}\left(p 98_{\text {ann }}\right)$ or $p 98_{\text {ann }}\left(\right.$ mean $\left._{\text {ens }}\right)$, but the decadal variability decreases over time.

At all grid-points, mean $_{e n s}\left(p 98_{a n n}\right)$ is higher than $p 98_{\text {ann }}\left(\right.$ mean $\left._{\text {ens }}\right)$, particularly in the early decades. This is expected as the ensemble mean is an average and therefore a smoothed representation of the extremes in the individual ensemble members. The extremes in the ensemble members may be displaced from the extreme events in the ensemble mean both in time and space. These differences between $\operatorname{mean}_{\text {ens }}\left(p 98_{a n n}\right)$ and $p 98_{a n n}\left(\right.$ mean $\left._{\text {ens }}\right)$, amount to around $0.5 \mathrm{~m} / \mathrm{s}$ in the late $19^{\text {th }}$ century (somewhat less in Zurich) but then decrease over time at all locations, probably due to a general decrease in the ensemble spread. The differences are larger for $\max _{a n n}$ (not shown). The closer the ensemble members are to each other, the more realistic is the ensemble mean. The ensemble range of the percentiles, i.e., $\max _{e n s}\left(p 98_{a n n}\right)-\min _{e n s}\left(p 98_{a n n}\right)$ also decreases over time. The change relative to the period 1950-2008 is shown in Figure 6. The figure shows that after around 1950, the range does not change much anymore. Between 1870 and 1950, the range decreases (in fact halves). The decrease is smaller for Zurich than for the other sites.

Errors common to all ensemble members could affect trend analyses. Such errors could originate from the data assimilated (e.g., inhomogeneities), inhomogeneities in the boundary conditions of the simulations (such as seasurface temperatures or sea-ice) and radiative forcing (due to $\mathrm{CO}_{2}$, solar irradiance changes, stratospheric and tropospheric aerosols), or from changes in the assimilation system itself. One example for the last factor are the changes in variance inflation factors used in the assim- 
ilation scheme (see Compo et al., 2011). The inflation factors were changed between 1890 and 1891 (globally), 1920 and 1921 (globally), and 1951 and 1952 (tropics and southern hemisphere) (arrows in Figure 6). The last date coincides with the levelling out of the ensemble spread, but at that time the variance inflation factor did not change in the northern extratropics. Overall, there is no clear indication of a link between changes in the variance inflation factors and changes in the ensemble spread of the percentiles.

\subsection{Linear trends in extremes}

The change in the ensemble spread $\max _{e n s}\left(p 98_{a n n}\right)-$ $\min _{\text {ens }}\left(p 98_{\text {ann }}\right)$ could indicate that low-frequency variability or trends in wind extremes in the ensemble might be affected by changes in the ensemble spread. Are trends calculated from the individual ensemble members more reliable than that calculated form the ensemble mean? To address this we calculated linear trends in $\max _{a n n}$ and $p 98_{a n n}$ for the three locations. Note that linear trends may not be a suitable model for representing the changes in the time series over longer periods. Particularly, Figure 5 shows that decadal-tomultidecadal variability is strong while linear trends are not obvious. Nevertheless, for illustrative purposes, we investigate linear trends in the following to address differences between trends of the ensemble mean compared to trends of individual ensemble members.

We calculated trends for each individual ensemble member and then plotted the frequency distribution of trends as a box plot, i.e., $\min _{\text {ens }}\left(\operatorname{trend}\left(p 98_{a n n}\right)\right)$, $p 10_{\text {ens }}\left(\operatorname{trend}\left(p 98_{\text {ann }}\right)\right), p 25_{\text {ens }}\left(\operatorname{trend}\left(p 98_{\text {ann }}\right)\right), p 50_{\text {ens }}$ $\left(\operatorname{trend}\left(p 98_{\text {ann }}\right)\right), \quad p 75_{\text {ens }}\left(\operatorname{trend}\left(p 98_{\text {ann }}\right)\right), \quad p 90_{\text {ens }}$ $\left(\operatorname{trend}\left(p 98_{a n n}\right)\right), \max _{\text {ens }}\left(\operatorname{trend}\left(p 98_{\text {ann }}\right)\right)$, and mean $\left(\operatorname{trend}\left(p 98_{a n n}\right)\right)$ (and the same with $\max _{a n n}$ instead of $\left.p 98_{a n n}\right)$. We compared this with the trends of percentile series shown in Figure 5, i.e., $\operatorname{trend}\left(p 10_{\text {ens }}\left(p 98_{\text {ann }}\right)\right)$ and $\operatorname{trend}\left(p 90_{\text {ens }}\left(p 98_{\text {ann }}\right)\right)$ as well as with the trend of the ensemble mean, i.e., $\operatorname{trend}\left(p 98_{\text {ann }}\left(\right.\right.$ mean $\left.\left._{\text {ens }}\right)\right)$ and $\operatorname{trend}\left(\max _{a n n}\left(\operatorname{mean}_{\text {ens }}\right)\right)$.

The trends were calculated for two periods: 18712008 (the entire period) and 1950-2008 (the period which according to Figure 6 does not show large changes in the spread). For trends in $p 98_{a n n}$ we used a linear regression model fitted with ordinary leastsquares. The residuals were close to normally distributed in all cases (not shown), and there was no significantly positive serial correlation (for Minneapolis, several ensemble members showed significantly negative firstorder serial correlation, however, due to the lack of a physical explanation, we considered this correlation to having occurred by chance and did not account for it statistically). Trends in $\max _{a n n}$ were obtained by fitting a generalised extreme value (GEV) distribution with shape, scale, and location parameter, the latter of which depends linearly on time. The GEV distribution was
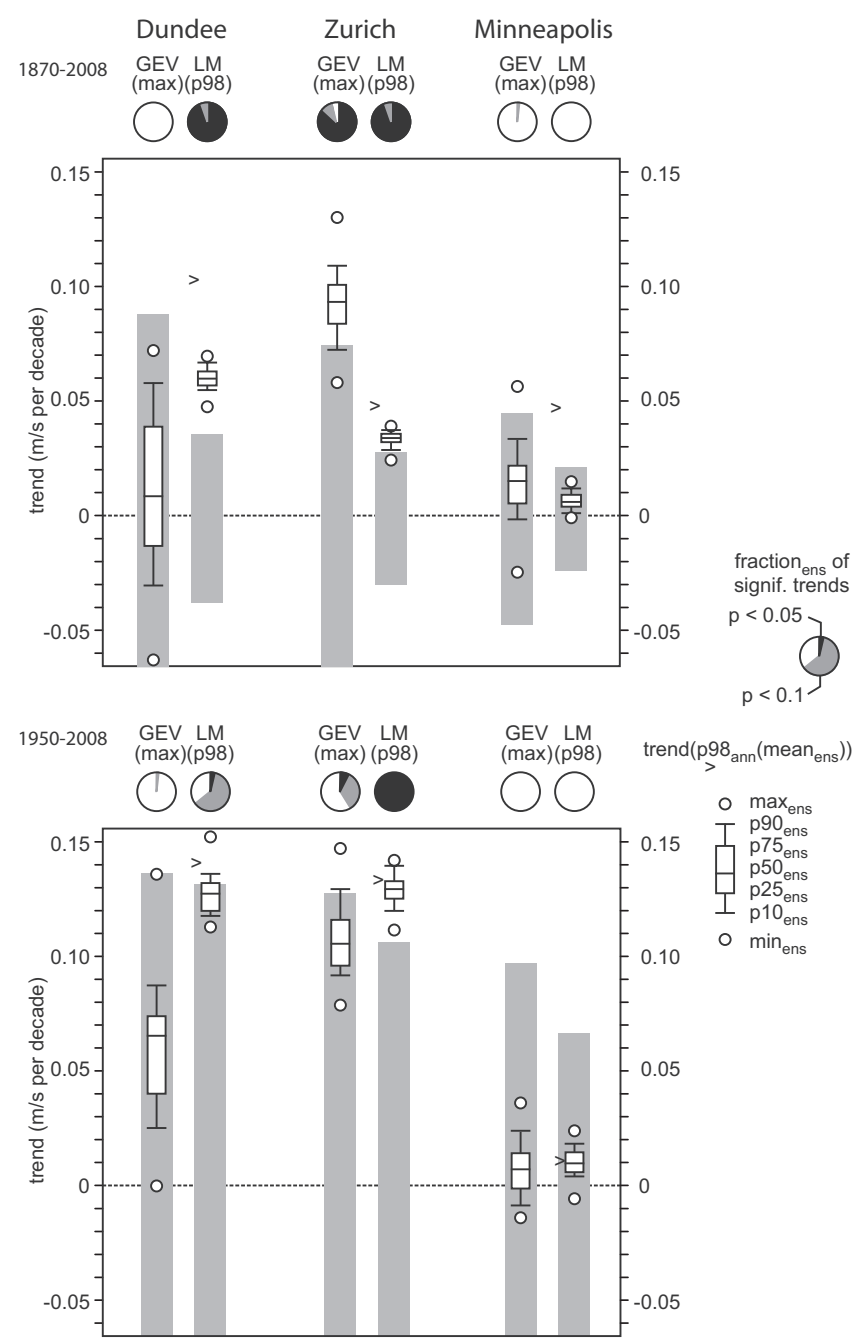

Figure 7: Trends in $p 98_{a n n}$ and $\max _{a n n}$ at three locations over two time periods 1871-2008 (top) and 1950-2008 (bottom). Trends were calculated for individual ensemble members, the box plot indicates the spread across the ensemble members. The pie diagram indicates the fraction of members displaying a significant trend $(p<0.1$ or $p<0.05$ in grey and black respectively). The grey shading denotes twice the ensemble mean of the standard error of the trend as an approximation of trend uncertainty. Arrow heads indicate trends derived from the ensemble mean wind field. GEV denotes trend calculated by fitting a GEV distribution whose location parameter depends linearly on time, while LM denotes a linear least-squares fit.

fitted using the maximum likelihood method (function gev.fit in R).

Trends are displayed in Figure 7. They confirm the discussion of Figure 5, namely that trends are near zero for Minneapolis and mostly positive for the other sites, and that, at the latter two sites, they are more positive in the 1950-2008 period. In these cases, trends in $p 98_{a n n}$ are larger than in $\max _{a n n}$, and the spread of trends within the ensemble is smaller for $p 98_{\text {ann }}$ than for $\max _{a n n}$. In fact, the trend differences in $p 98_{a n n}$ between the ensemble members are small compared with the trend uncertainties (the shaded areas in Figure 7 in- 
dicate twice the ensemble mean standard error of the trend coefficients as an approximation of the trend uncertainty; note that for each ensemble member the exact trend uncertainty would be slightly different). The same also holds for $\max _{a n n}$. Hence, the uncertainty in the trend coefficient is much larger than trend differences between ensemble members. There are hardly any significant trends for $\max _{a n n}$. Analysing the trend in extremes derived from the ensemble mean, we find that it is always larger than the median of the trends in the individual members and often larger than in any of the individual ensemble members. In fact, the trend in the ensemble mean may be significant even if none of the members is (e.g., in Minneapolis, 1871-2008). The fraction of significant trends among the ensemble members is illustrated by the pie charts located near the top of Figure 7. Note that many of the trends are not significant.

In all, we find positive trends in strong and extreme wind speeds at the two European sites on the order of $10-15 \mathrm{~mm} / \mathrm{s}$ per year (corresponding to $1-1.5 \mathrm{~m} / \mathrm{s}$ per century) over the 1950-2008 period, but robust significance (in the following defined as $>90 \%$ of the ensemble members showing a trend that is significant at the $95 \%$ level) is only found for Zurich. Note that we have only discussed the uncertainties in the data sets and the differences arising from using different measures. We have not addressed the choice of the statistical model and the estimators used. Hence, there are other components of structural uncertainty that are not accounted for in this study. However, the results show that trends calculated from the ensemble mean may lie outside the range spanned by the trends calculated from each individual ensemble member.

\subsection{Spatial analysis of trends}

In this section, we address the question of how representative the findings for the three exemplary sites are of trends in extreme winds in the northern hemisphere. We apply the trend analysis discussed before to 20CR grid points of the northern hemisphere and present the spatial distribution of wind speed trends. We only analyse northern mid-latitudes, for which we have assessed the data in Sections 3 and 4.

The results for the three sites have shown that the ensemble spread in extreme winds changes over time. To illustrate this behaviour for all grid points we analyse the reduction of the within-ensemble variability of the corresponding variables over time, similar as in Figure 6 but for all grid-points in the Northern Hemisphere. Figure 8 illustrates this by relating the spread for the year 1879 (i.e., the year of the Tay Bridge storm) to that for the year 2007 (i.e., the year the windstorm Kyrill occurred). For $p 98$ the inflation/reduction of the spread (here displayed in the form of standard deviations) in 1879 compared to 2007 is small over Europe and eastern USA and to some extent also in the Atlantic storm track region, but large in other regions (especially in

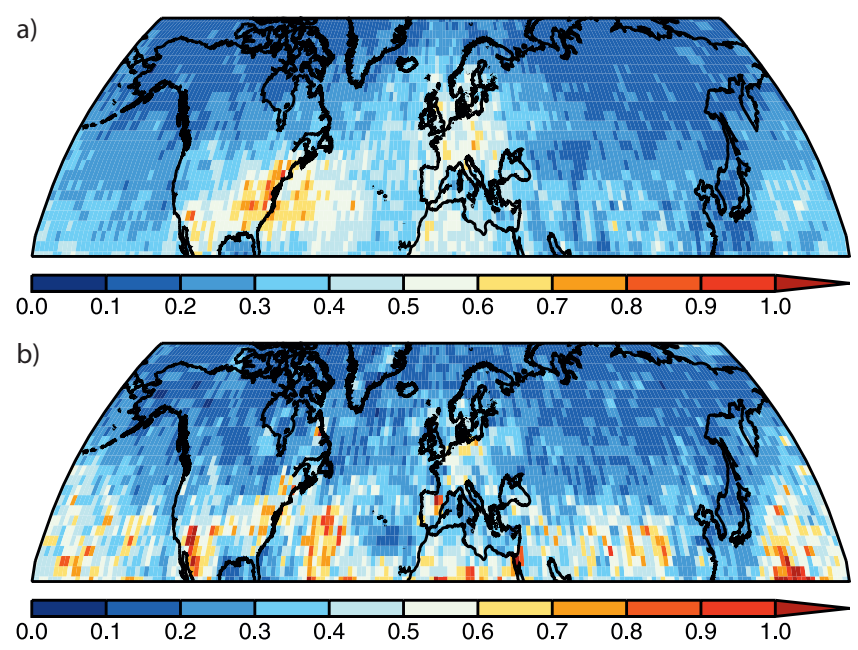

Figure 8: a) stddevens $\left(p 98_{2007}\right)$ divided by $\operatorname{stddev} v_{e n s}\left(p 98_{1879}\right)$. b) Same as a) but for max.

the high latitudes). The spatial pattern is similar, though less coherent, for max. As a consequence, and similar as for the three grid locations, we display trends only for the period after 1950 in the following. We use the same measures and statistical methods as before, i.e., we calculate $\operatorname{trend}\left(p 98_{a n n}\right)$ and $\operatorname{trend}\left(\max _{a n n}\right)$ and fit the coefficients in the same way. For simplicity, we now show the mean of the trends of all individual ensemble members, i.e., mean $_{\text {ens }}\left(\operatorname{trend}\left(p 98_{\text {ann }}\right)\right)$ and $\operatorname{mean}_{\text {ens }}\left(\operatorname{trend}\left(\max _{a n n}\right)\right)$. Furthermore, trends are only plotted if they show robust significance $(>90$ $\%$ of the ensemble members showing a significant trend at the $95 \%$ confidence level). Results are shown in Figure 9, together with selected contours of mean $n_{e n s}$ $\left(p 98_{a n n}\right)$ and $\operatorname{mean}_{\text {ens }}\left(\max _{a n n}\right)$ for the period 19502008 in order to show the North Pacific and North Atlantic storm track regions.

Trends for $p 98_{\text {ann }}$ (top panel) are positive in the centre and to the northeast of the North Atlantic storm track area (to which Dundee is bordering). The area with positive trends reaches into the European continent (including Zurich). Negative trends are found near the Azores. The pattern corresponds to a strengthening and possibly a poleward shift of the area of strong winds. The trend structure in the North Pacific is consistent with a southward shift of the storm track region over the western Pacific. The relation to trends in tropical cyclones undergoing extratropical transition remains to be explored. Over the remaining continental regions, trends are mostly negative, especially over China, but positive in the Canadian Arctic.

The picture is similar for the trend in $\max _{a n n}$ (bottom panel). However, there are few grid-points with robust significant trends. Without going through the process of estimating spatial significance and the number of independent samples, it becomes visually apparent that trends in $\max _{a n n}$ are, at most, local. 


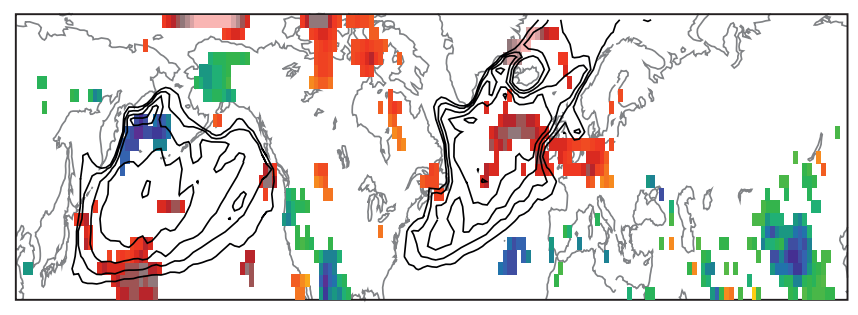

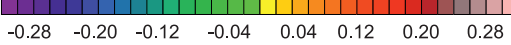

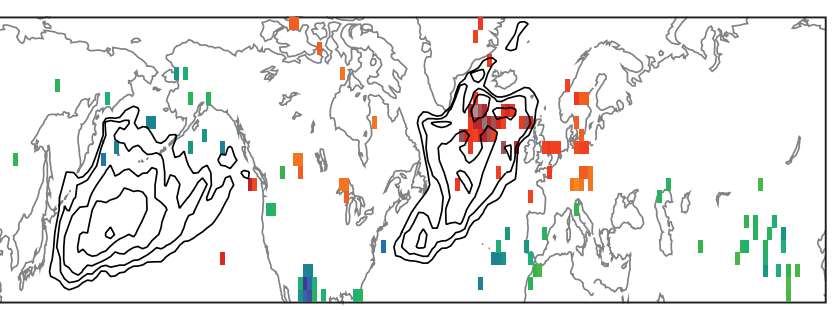

$\begin{array}{lllllllll}-0.84 & -0.60 & -0.36 & -0.12 & 0.12 & 0.36 & 0.60 & 0.84 & \mathrm{~m} / \mathrm{s} \text { per decade }\end{array}$

Figure 9: Map of the trend in $p 98_{a n n}$ (top) and $\max _{a n n}$ (bottom) for the period 1950-2008. Shown is the ensemble mean of the trend (i.e., $\operatorname{mean}_{e n s}\left(\operatorname{trend}\left(p 98_{a n n}\right)\right)$ and $\operatorname{mean}_{e n s}\left(\operatorname{trend}\left(\max _{a n n}\right)\right)$, respectively), but only if $90 \%$ of the ensemble members exhibit a significant $(p<0.05)$ trend. Contours denote the ensemble average of $p 98_{a n n}$ and $\max _{a n n}$, respectively, with contours starting at 20 $\mathrm{m} / \mathrm{s}$ (top) and $30 \mathrm{~m} / \mathrm{s}$ (bottom) and an interval of $1 \mathrm{~m} / \mathrm{s}$.

Previous studies have targeted trends in extreme winds by using other reanalysis data sets or by estimating geostrophic winds from SLP from station triangles. The results are generally in good agreement with our findings. MATULLA et al. (2008) found no significant overall trend in extreme wind speeds over Europe during the past 130 years, but intermittent decadal changes that make trend detection difficult. WANG et al. (2009) argued that winter storminess shows an unprecedented maximum in the early 1990s in the North Sea area (which we also find) and a steady upward trend in the north-eastern part of the region, while storminess has declined in the western part of the North Sea area. WANG et al. (2011) analysed extremes of geostrophic wind speeds derived from sub-daily surface pressure observations at 13 sites in the European region from the Iberian Peninsula to Scandinavia for the period from 1878 to 2007. Trends in winter storminess are characterised by increases in the Alpine region, and slight decreases in northern Europe and in the region from the northwestern Iberian Peninsula northeastward to the southern UK (WANG et al., 2011). DONAT et al. (2011), based on 20CR, find a long-term increase in storminess over the North Atlantic region and an unprecedented peak in the 1990s. USBECK et al. (2010a, b) combined historical data with early instrumental measurements and found an increase in storm damage in Switzerland since the mid19th century.

Trends in extreme winds from reanalysis do not always agree with trends in observed extreme winds.
SMITS et al. (2005) found decreasing extreme winds over the Netherlands in observations from the period 1962-2002 but increasing trends in the reanalysis data sets that they studied. For the case of Zurich, the comparison of the wintertime $93^{\text {rd }}$ percentile also indicates differences at the multidecadal scale. Apart from errors in the data sets, increases in the roughness over land due to increasing biomass could lead to different trends in land observations and reanalyses (VAUTARD et al., 2010), often termed "atmospheric stilling".

In other areas, such as for the decreasing trend of wind extremes over China, reanalysis data and observations fit better (JIANG et al., 2010). A decreasing trend is not only found in observed surface mean and maximum wind speeds over the period 1956-2004, but also in reanalysis data at higher atmospheric levels. The apparent trend in wind speed over China has been attributed to the fact that the temperature difference between the Asian continent and the Pacific Ocean has decreased and the east Asian trough has weakened and shifted northeastward, along with a weakening of both winter and summer monsoons over China (JIANG et al., 2010).

\section{Conclusions}

The analyses of extreme weather and climate events can benefit from an extension in length of available temporally high resolved data sets such as 20CR. However, a number of factors need to be considered depending on the application and the case considered. These are illustrated using four examples of wind extremes at mid-latitudes. It is shown that for individual storms, 20CR provides a good depiction of the synoptic meteorological situation and development. Local features that are related to smaller-scale or topographically induced processes are not necessarily captured by 20CR. For analysing trends of extreme winds, we show that the ensemble mean may not be suited. The trend in the ensemble mean may lie outside the range of the trend derived from the individual ensemble members. For the three studied locations in Europe and North America, we find that the period after 1950 is better suited for trend analysis than the period before due to changes in the ensemble variance. Finally, a map of trends in extreme wind speeds since 1950 shows that the annual $98^{\text {th }}$ percentile of wind speed exhibits changes towards more extreme winds in the North Atlantic storm track region (or a poleward shift), decreasing wind extremes over the northern subtropics (especially China), and an equatorward shift of the Pacific storm track. For trends in annual maximum wind speeds, we find few significant regions.

New numerical approaches such as 20CR and future, improved products may change historical climatology. However, we suggest that combining reanalysis information with information from other data sources such as observations or proxies (currently targeted by many 
activities) will increase the confidence in statements related to trends and variability in extreme winds.

\section{Acknowledgments}

This work was funded by the Swiss National Science Foundation through project EVALUATE and through the National Competence Centre on Research (NCCR) in Climate. Juerg LUTERBACHER acknowledges support by the project "Climate Change and Extreme Weather in Hessen - Analysis of observation data and ensemble projections for the $21^{\text {st }}$ century" funded by the Hessian Centre on Climate Change and Geology. Juerg LUTERBACHER is also supported by the EU/FP7 project ACQWA (\#212250). We acknowledge helpful comments by Thomas WOHLGEMUTH (WSL, Switzerland). 20CR data were obtained courtesy of the NOAA/OAR/ESRL PSD, Boulder, Colorado, USA, from their Web site at www.esrl.noaa.gov/psd/. Support for the Twentieth Century Reanalysis Project dataset is provided by the U.S. Department of Energy, Office of Science Innovative and Novel Computational Impact on Theory and Experiment (DOE INCITE) program, and Office of Biological and Environmental Research (BER), and by the NOAA Climate Goal. The Project used resources of the National Energy Research Scientific Computing Center and of the National Center for Computational Sciences at Oak Ridge National Laboratory, which are supported by the Office of Science of the U.S. Department of Energy under Contract No. DE-AC02-05CH11231 and Contract No. DE-AC0500OR22725, respectively. We acknowledge the data providers in the ECA\&D project (http://eca.knmi.nl).

\section{References}

Allan, R., P. Brohan, G.P. Compo, R. Stone, J. LUTERBACHER, S. BRÖNNIMANN, 2011: The International Atmospheric Circulation Reconstructions over the Earth (ACRE) Initiative. - Bull. Amer. Meteor. Soc. 92, 1421-1425.

Alexandersson, H., H. TuOmenvirta, T. Schmith, K. IDEN, 2000: Trends of storms in NW Europe derived from an updated pressure data set. - Climate Res. 14, 7173.

B ÄRRING L., K. FORTUNIAK, 2009: Multi-indices analysis of southern Scandinavian storminess 1780-2005 and links to interdecadal variations in the NW Europe-North Sea region. - Int. J. Climatol. 29, 373-384.

BÄRRING L., H. VON STORCH, 2004: Scandinavian storminess since about 1800. - Geophys. Res. Lett. 31, L20202.

BRÁzDIL R., P. Dobrovolný, 2000: Chronology of strong wind events in the Czech lands during the 16th-19th centuries. - IGU J-Prace Geograficzne 107, 65-70.

—, - 2001: History of strong winds in the Czech lands. causes, fluctuations, impacts. - Geogr. Pol. 74, 11-27.

BRÖNNIMANN, S., G.P. Compo, 2012: Ozone highs and associated flow features in the first half of the twentieth century in different data sets. - Meteorol. Z. 21, 049-055.
BRÖNNIMANN, S., T. EWEN, J. LUTERBACHER, 2009: Variability of the global atmospheric circulation during the past 100 years. - Meteorol. Z. 18, 365-368.

BURT, P.J.A. 2004: The great storm and the fall of the first Tay Rail Bridge. - Weather 59, 347-350.

Cleveland, W.S., E. Grosse, W.M. Shyu, 1992: Local regression models. - In: CHAMBERS, J.M., T.J. HASTIE (Eds.): Statistical Models in S. Chapman and Hall.

Coelho, C.A.S., C.A.T. Ferro, D.B. Stephenson, D.J. SteinsKog, 2008: Methods for Exploring Spatial and Temporal Variability of Extreme Events in Climate Data. - J. Climate 21, 2072-2092.

Coles, S., 2001: An introduction to statistical modeling of extreme values. - Springer Series in Statistics, 228 pp.

COMPo, G.P., J.S. WhitAKER, P.D. SARDESHMUKH, N. Matsui, R.J. Allan, X. Yin, B.E. Gleason, R.S. Vose, G. Rutledge, P. Bessemoulin, S. Brönnimann, M. Brunet, R.I. Crouthamel, A.N. Grant, P.Y. Groisman, P.D. JONES, M.C. KRUK, A.C. Kruger, G.J. Marshall, M. Maugeri, H.Y. MoK, Ø. Nordli, T.F. Ross, R.M. TRIGO, X.L. WAnG, S.D. WoOdRufF, S.J. Worley, 2011: The Twentieth Century Reanalysis project. - Quart. J. Roy. Meteor. Soc. 137, 1-28.

DAVison, A.C., R.L. SMith, 1990: Models for Exceedance over High Threshold. - J. Roy. Stat. Soc. B 52, 393-442.

DeE, D.P., S.M. UpPala, A.J. Simmons, P. BerrisFORD, P. POlI, S. KobAYAShI, U. ANDraE, M.A. Balmaseda, G. BAlsamo, P. BAuer, P. BeCHTOLD, A.C.M. BElJAARS, L. VAN DE BERG, J. BIDlot, N. Bormann, C. Delsol, R. Dragani, M. Fuentes, A.J. Geer, L. Haimberger, S. B. Healy, H. Hersbach, E. V. Hólm, L. ISAKSEN, P. KÅllbERG, M. Köhler, M. Matricardi, A. P. MCNally, B. M. Monge-SAnz, J.-J. Morcrette, B.-K.PARK, C. Peubey, P. De Rosnay, C. Tavolato, J.-N. Thépaut, F. VITART, 2011: The ERA-Interim reanalysis: configuration and performance of the data assimilation system. Quart. J. Roy. Meteor. Soc. 137, 553-597.

Della-Marta, P.M., H. Mathis, C. Frei, M.A. LiNIGER, J. KleinN, C. APPENZELler, 2009: The return period of wind storms over Europe. - Int. J. Climatol. 29, 437-459.

Dijkstra, H.A., L. TeRAa, M. Schmeits, J. GerRits, 2006: On the physics of the Atlantic Multidecadal Oscillation. - Ocean Dynam. 56, 36-50.

DobrovolnÝ, P., R. BRÁZDIL, 2003: Documentary evidence on strong winds related to convective storms in the Czech Republic since AD 1500. - Atmos. Res. 67, 95-116.

Donat, M.G., D. Renggli, S. Wild, L.V. AlexanDER, G.C. LECKEBUSCH, U. UlbRICH, 2011: Reanalysis suggests long-term upward trends in European storminess since 1871. - Geophys. Res. Lett. 38, L14703, DOI:10.1029/2011GL047995.

DRECHSEL, S., G. MAYR, 2008: Objective forecasting of foehn winds for a subgrid-scale Alpine valley. - Wea. Forecast. 23, 205-218.

Dupigny-Giroux, L. A., T.F. Ross, J.D. Elms, R. TRUESDELL, S.R. DoTY, 2007: NOAA's climate database modernization program: Rescuing, archiving, and digitizing history. - Bull. Amer. Meteor. Soc. 88, 1015-1017.

Fink, A.H., T. Brücher, V. Ermert, A. KrüGer, J.G. PINTO, 2009: The European storm Kyrill in January 2007: synoptic evolution, meteorological impacts and some considerations with respect to climate change. - Nat. Hazards Earth Syst. Sci. 9, 405-423. 
FRANK, H.P., D. MAJEWSKI, 2006: Hindcasts of historic storms with the DWD models GME, LMQ and LMK using ERA-40 reanalyses. - Newsletter 109, ECMWF, Reading.

FREI, C., C. SCH ÄR, 2001: Detection probability of trends in rare events: theory and application to heavy precipitation in the Alpine region. - J. Climate 14, 1568-1584.

FREY, H., 1926: Die lokalen WInde am Zürichsee. - Neujahrsblatt der Naturforschenden Gesellschaft Zürich 128, $40 \mathrm{pp}$.

HofHerr, T., M. Kunz, 2010: Extreme wind climatology of winter storms in Germany. - Climate Res. 41, 105-123.

Hurrell, J.W., Y. Kushnir, G. Ottersen, M. VisBECK, 2003: An Overview of the North Atlantic Oscillation. - In: Hurrell, J.W., Y. KuSHNIR, G. OTTERSEN, M. VISBEcK (Eds.): The North Atlantic Oscillation. Climatic significance and environmental impact. - Amer. Geophys. Union Geophys. Mono. 134, 1-35.

IPCC, 2011: Summary for Policymakers. In: Intergovernmental Panel on Climate Change Special Report on Managing the Risks of Extreme Events and Disasters to Advance Climate Change Adaptation [FIELD, C.B., V. BARROS, T.F. STOCKER, D. QIN, D. DOKKEN, K. L. EBI, M.D. Mastrandrea, K.J. Mach, G.-K. Plattner, S. Allen, M. Tignor, P.M. Midgley (Eds.)]. - Cambridge University Press, Cambridge, United Kingdom and New York, NY, USA

JiANG, Y., Y. LUO, Z.C. ZHAO, S.W. TAO, 2010: Changes in wind speed over China during 1956-2004. - Theor. Appl. Climatol. 99, 421-430.

JohnSON, E.A., K. MIAYNISHI, 2007: Plant disturbance ecology: the process and the response. - Elsevier, Amsterdam, $720 \mathrm{pp}$.

JÖNSSON, P., K. FORTUNIAK, 1995: Interdecadal variations of surface wind direction in Lund, southern Sweden, 17411990. - Int. J. Climatol. 15, 447-461.

JÖNSSON, P., B. HoLMQUIST, 1995: Wind directions in southern Sweden 1740-1992: variation and correlation with temperature and zonality. - Theor. Appl. Climatol. 51, 183-198.

Jungo, P., S. Goyette, M. Beniston, 2002: Daily wind gust speed probabilities over Switzerland according to three types of synoptic circulation. - Int. J. Climatol. 22, $\underline{485-499 .}$

KALthoFF, N., I. BischofF-GAuss, F. FIEDLER, 2003: Regional effects of large-scale extreme wind events over orographically structured terrain. - Theor. Appl. Climatol. 74, 53-67.

KLAWA, M., U. ULBRICH, 2003: A model for the estimation of storm losses and the identification of severe winter storms in Germany. - Nat. Hazards Earth Syst. Sci. 3, 725732.

Klein TAnK, A.M.G., F.W. Zwiers, X. Zhang, 2009: Guidelines on analysis of extremes in a changing climate in support of informed decisions for adaptation. - Climate Data and Monitoring WCDMP-No. 72, WMO-TD No. 1500, 56 pp.

KLOK, E.J., A.M.G. KLEIN TANK, 2009: Updated and extended European dataset of daily climate observations. Int. J. Climatol. 29, 1182-1191.

KNARR, A.J., 1941: The Midwest storm of November 11, 1940. - Mon. Wea. Rev. 69, 169-178.

KrUEGER, O., H. vON STORCH, 2011: Evaluation of an air pressure based proxy for storm activity, - J. Climate 24, 2612-2619.
KYSELÝ, J., 2010: Recent severe heat waves in central Europe: how to view them in a long-term prospect? - Int. J. Climatol. 30, 89-109.

LAMB, H., 1991: Historic storms of the North Sea, British Isles and Northwest Europe. - Cambridge University Press, 228 pp.

Leckebusch, G. C., U. Ulbrich, L. FrÖhlich, J.G. PINTO, 2007: Property loss potentials for European midlatitude storms in a changing climate. - Geophys. Res. Lett. 34, L05703, DOI: 10.1029/2006/GL027663.

Matulla, C., W. Schöner, H. Alexandersson, H. VON STORCH, X.L. WANG, 2008: European storminess: late 19 th century to present. - Climate Dynam. 31, 1125130.

Matulla, C., M. Hofstätter, I. Auer, R. Böhm, M. MAugeri, H VON STORCH, O. KRUEGer, in press: Storminess in Northern Italy and the Adriatic Sea reaching back to 1760 . - Phys. Chem. Earth, DOI:10.1016/j.pce.2011.04.010.

Palutikof, J.P., B.B. Brabson, D.H. Lister, S.T. AdCOCK, 1999: A review of methods to calculate extreme wind speeds. - Meteor. Appl. 6, 119-132.

PASCAL, G., 2010: Zyklonen Tracking von intensiven Stürmen. - Semesterarbeit, ETH Zürich, Switzerland.

Pfahl, S., F. Sirocko, K. Seelos, S. Dietrich, A. WAlter, H. Wernli, 2009: A new windstorm proxy from lake sediments: a comparison of geological and meteorological data from western Germany for the period 1965-2001. - J. Geophys. Res. 114, D18106, DOI:10.1029/2008JD011643.

Pfister, C., 2009: The "disaster gap" of the 20th century and the loss of traditional disaster memory. - GAIA Ecological Perspectives for Science and Society 18, 239246.

Pfister, C., E. Garnier, M.-J.Alcoforado, D. WHEELER, J. LutERBACHER, J.P. TABORDA, 2010: The meteorological framework and the cultural memory of three severe winter-storms in early eighteenth-century Europe. - Climatic Change 101, 281-310.

Rayner, N.A., D.E. PArker, E.B. Horton, C.K. FolLAND, L.V. AleXANDER, D.P. Rowell, E.C. Kent, A. KAPLAN, 2003: Global analyses of sea surface temperature, sea ice, and night marine air temperature since the late nineteenth century. - J. Geophys. Res. 108, 4407, DOI:10.1029/2002JD002670.

RENGGli, D., G.C. LECKEBUSCH, U. UlbriCh, S.N. GLEIXNER, E. FAUST, 2011: The skill of seasonal ensemble prediction systems to forecast wintertime windstorm frequency over the North Atlantic and Europe. - Mon. Wea. Rev. 139, 3052-3068.

Rootzén, H., N. TAJVIDI, 1997: Extreme value statistics and wind storm losses: a case study. - Scandinavian Actuarial J. 1, 70-94.

ŠÁLEK, M., P. ŠTĚPÁNEK, P. ZAHRADNÍČEK, 2012: Analysis of rainfall intensities using very dense network measurements and radar information for the Brno area during the period 2003-2009. 2003-2009. - Meteorol. Z. 21, 029-036.

Schiesser, H.H., C. Pfister, J. BAder, 1997: Winter storms in Switzerland North of the Alps 1864/18651993/1994. - Theor. Appl. Climatol. 58, 1-19. 
Schumacher, S., H. Bugmann, 2006: The relative importance of climatic effects, wildfires and management for future forest landscape dynamics in the Swiss Alps. - Glob. Change Biol. 12, 1435-1450.

SchumaCher, S., H. Bugmann, D.J. Mladenoff, 2004: Improving the formulation of tree growth and succession in a spatially explicit landscape model. - Ecol. Model. 180, 175-194.

SChwierz, C., P. Köllner-Heck, E. Zenklusen MutTER, D.N. BRESCH, P.-L. Vidale, M. WILD, C. SCHÄR, 2010: Modelling European winter wind storm losses in current and future climate. - Climatic Change 101, 485-514.

Smits, A., A.M.G. Klein Tank, G.P. Können, 2005: Trends in storminess over the Netherlands, 1962-2002. Int. J. Climatol. 25, 1331-1344.

Stephenson, D.B. 2008: An Introduction to Probability Forecasting. - In: TrocCOLLI, A., et al. (Eds.): Seasonal Climate: Forecasting and Managing Risk. - Springer, 93129.

Stickler, A., A. N. Grant, T. Ewen, T. F. Ross, R. S. Vose, J. Comeaux, P. Bessemoulin, K. Jylhä, W. K. Adam, P. Jeannet, A. NAgurny, A. M. Sterin, R. Allan, G. P. COMPo, T. GRIESSER, S. BrönNimAnN, 2010: The Comprehensive Historical Upper Air Network (CHUAN). - Bull. Amer. Meteor. Soc. 91, 741-751.

Truchelut, R.E., R.E. HART, 2011: Quantifying the possible existence of undocumented Atlantic warmcore cyclones in NOAA/CIRES 20th Century Reanalysis data. - Geophys. Res. Lett. 38, L08811, Doi:10.1029/2011GL046756.

Usbeck, T., T. Wohlgemuth, M. Dobbertin, C. PfisTER, A. BÜRGI, M. REBETEZ, 2010a: Increasing storm damage to forests in Switzerland from 1858 to 2007. - Agr. Forest Meteor. 150, 47-55.

Usbeck, T., T. Wohlgemuth, C. Pfister, R. Volz, M. Beniston, M. DobBertin, 2010b: Wind speed mea- surements and forest damage in Canton Zurich (Central Europe) from 1891 to winter 2007. - Int. J. Climatol. 30, 347 358.

Ustrnul, Z., A. WypyCh, M. KosowsKi, 2011: Extreme temperatures and precipitation in Poland - an evaluation attempt. - Meteorol. Z. 21, 037-047.

Vautard, R., J. CattiauX, P. Yiou, J.-N. Thépaut, P. CIAIS, 2010: Northern Hemisphere atmospheric stilling partly attributed to an increase in surface roughness. - Nat. Geosci. 3, 756-761.

von Storch, H., J. Perlwitz, J. Guddal, K.A. Iden, M. Reistad, T. JONSSON, J. DE RONDE, E. ZoRITA, H. SCHMIDT, 1993: Changing statistics of storms in the North Atlantic? - Max-Planck-Institute Meteor. Rep. 116, 19 pp.

WANG, X.L., F.W. ZwiERs, V.R. SWAIL, Y. FENG, 2009: Trends and variability of storminess in the Northeast Atlantic region, 1874-2007. - Climate Dynam. 33, 11791195.

WANG, X.L., H. WAN, F.W. ZWIERS, V.R. SWAIL, G.P. Compo, R.J. Allan, R.S. Vose, S. Jourdain, X. YIN, 2011: Trends and low-frequency variability of storminess over western Europe, 1878-2007. - Climate Dynam. 37, 2355-2371.

WASA, 1998: Changing waves and storms in the Northeast Atlantic? - Bull. Amer. Meteor. Soc. 79, 741-760.

Weber, R.O., M. Furger, 2010: Climatology of nearsurface wind patterns over Switzerland. - Int. J. Climatol. 21, 809-827.

WERNLI, H., S. DIRREN, M.A. LINIGER, M. ZILliG, 2002: Dynamical aspects of the life cycle of the winter storm 'Lothar' (24-26 December 1999). - Quart. J. Roy. Meteor. Soc. 128, 405-429.

Wheeler, D., R. Garcia- Herrera, C. W. WilkinSON, C. WARD, 2010: Atmospheric circulation and storminess derived from Royal Navy logbooks: 1685 to $1750 .-$ Climate Change 101, 257-280. 